\title{
NILAI AGAMA HINDU DALAM GAMELAN GAMBANG
}

\author{
I Wayan Sukadana \\ Fakultas Pendidikan Agama dan Seni \\ Universitas Hindu Indonesia \\ e-mail: nanounhi108@yahoo.com
}

\begin{abstract}
Art and religion for the Hindu community in Bali can not be separated. It can be proven, in the implementation of yadnya ceremony conducted by Balinese Hindus. Gambang Gamelan is a gamelan of old class has Laras Pelog Seven Tones. Physically Gambang Gamelan is formed by bladed instruments by producing the color of Bamboo and Copper Bars. As one of art form, Barungan Gamelan Gambang in Bali, has strategic position and important in activity which is ritual especially in every area in Bali. Therefore, Gambang Gamelan needs to be preserved. The values of Hinduism contained in the Gambang Gamelan are: religious values, aesthetic values, and ethical values.
\end{abstract}

Keywords: Gambang Gamelan, Value of Hindu Religion

\begin{abstract}
Abstrak
Seni dan agama bagi masyarakat Hindu di Bali tidak bisa dipisahkan. Hal itu dapat dibuktikan, dalam pelaksanaan upacara yadnya yang dilakukan oleh umat Hindu Bali. Gamelan Gambang adalah gamelan golongan tua memiliki Laras Pelog Tujuh Nada. Secara fisik Gamelan Gambang dibentuk oleh instrumen berbilah dengan menghasilkan warna Suara bilahan Bambu dan Bilahan Tembaga. Sebagai salah satu bentuk kesenian, barungan Gamelan Gambang di Bali, memiliki kedudukan strategis dan penting dalam aktivitas yang bersifat ritual khususnya di setiap daerah di Bali. Oleh karena itu, Gamelan Gambang ini perlu dilestarikan. Nilai-nilai agama Hindu yang terkandung dalam Gamelan Gambang yaitu: nilai religi, nilai estetika, dan nilai etika.
\end{abstract}

Kata Kunci: Gamelan Gambang, Nilai Agama Hindu

\subsection{Pendahuluan}

Pengertian gamelan adalah ensambel musik dari Indonesia, biasanya dari pulau Bali atau Jawa. Kata gamelan sendiri berasal dari bahasa Jawa yaitu gamel yang berarti memukul / menabuh, diikuti akhiran an yang menjadikannya kata benda. Gamelan juga memiliki arti sebuah orkestra yang terdiri dari bermacam-macam instrumen yang terbuat dari batu, kayu, bambu, besi perunggu, kulit, dawai, dan lain-lainnya dengan menggunakan laras Pelog dan 
Selendro. Istilah gamelan dipakai juga untuk menyebutkan musik (lagu-lagu) yang dihasilkan oleh permainan instrumeninstrumen di atas. Dewasa ini ditemukan lebih dari 30 jenis perangkat gamelan Bali yang tersebar di seluruh kabupaten Bali dan masing-masing perangkat itu memiliki, fungsi, instrumentasi, orkestrasi, dan teknik permainan yang berbeda-beda (Bandem 2013:1).

Sejarah telah mencatat bahwa gamelan merupakan salah satu warisan dari produk budaya Agama Hindu di masa lalu. Gamelan adalah orkestra besar yang terdapat di pulau Jawa dan Bali. Gamelan Jawa Maupun gamelan Bali merupakan karya monumental dari nenek moyang bangsa Indonesia yang memiliki nilai setara dengan bangunanbangunan candi. Gamelan bisa tumbuh dan berkembang di masa lalu karena pada masamasa kerajaan Hindu, raja memberikan perhatian yang besar terhadap pertumbuhan dan perkembangan nilai-nilai seni dan budaya. Catatan sejarah membuktikan bahwa ketika kerajaan Hindu menjadi pusat kekuasaan di tanah Jawa, raja mendorong perkembangan sosial, politik, agama, kesusastraan, dan seni. Sejarah musik gamelan dapat ditelusuri dari periode awal kerajaan Hindu di Jawa Tengah abad ke-8 sampai abad ke-10 adalah pentingnya musik gamelan dan seni pertunjukan. Juga termasuk di dalamnya menulis dan membaca puisi Kekawin sebagai bagian dari pendidikan warga istana dan keluarga bangsawan. Anggota-anggota istana dari berbagai jenjang seperti : pendeta, pangeran, putri, dayang-dayang harus belajar memainkan musik gamelan, nyanyian, menari, atau berpuisi (Donder 2005:1).

Gambang adalah sebuah instrumen gamelan Bali yang menggunakan laras pelog tujuh nada, Gambang memiliki dua jenis instrumen, yaitu Gangsa atau sering disebut dengan Saron dan instrumen yang satu lagi disebut Gambang. Jumlah penabuh Gamelan Gambang berkisar antara lima sampai enam orang, tergantung dari banyaknya tungguhan dalam satu barungan. Gangsa atau Saron merupakan salah satu instrumen berbilah dengan bahan bilah yang terbuat dari bahan perunggu, sebaliknya Gambang, meskipun juga merupakan instrumen berbilah, namun bahan bilahnya terbuat dari bahan bambu. Dalam Barungan Gamelan Gambang, gangsa bertugas sebagai pembawa melodi sedangkan Gambang bertugas untuk membuat kotekan. Gamelan Gambang memiliki fungsi sebagai pengiring Upacara Dewa Yadnya dan Pitra Yadnya (Dibia, 7:1987)

Berdasarkan pengertian Gamelan Gambang tersebut, maka penulis dapat simpulkan bahwa Gamelan Gambang adalah sebuah instrumen musik tradisional yang telah menjadi warisan budaya Indonesia serta tak lepas dari kehidupan umat beragama Hindu khususnya di Bali, semua itu tercermin dari fungsi Gamelan Gambang itu sebagai pengiring dalam Upacara Dewa Yadnya dan Pitra Yadnya. Terlepas dari fungsinya sebagai pengiring dalam upacara, Gamelan Gambang juga memiliki pendalaman mengenai sistem organisasi, pemekaan rasa, sikap, mental, serta nilai-nilai pendidikan yang terkandung didalamnya.

Nilai merupakan sesuatu yang berharga dan berguna bagi manusia, dapat dijadikan pedoman menuju kehidupan yang lebih baik. Menurut Scheler menangkap nilai bukan dengan pikiran melainkan dengan sesuatu perasaan intensional. Perasaan ini tidak dibatasi pada perasaan fisik atau emosi, melainkan mirib dengan paham rasa dalam budaya jawa, sebagai keterbukaan hati dan budi dalam semua dimensi. Perasaan itu intensional karena setiap nilai ditangkap melalui perasaan yang terarah tepat padanya (Kanisisus, Etika abad 
20, 2006:17).

Suatu pertunjukan seni yang dipentaskan di bali secara mendasar memiliki suatu nilai nilai yang terkandung didalamnya. Dimana adanya sebuah kesenian ada dalam sebuah pelaksanaan upacara di bali pertunjukan seni dapat menguatkan pelaksanaan suatu upacara : (1) nilai religius, (2) nilai estetika, dan (3) nilai etika.

\subsection{Pembahasan}

\subsubsection{Nilai Religius}

Masyarakat Hindu di bali secara umum merupakan sekumpulan masyarakat yang tak lepas dari kegiatan aktivitas keagamaan yang dilaksanakan baik secara nitya karma maupun naimitika karma. Sejatinya aktivitas keagamaan diibaratkan sebagai sebuah alat untuk menghubungkan diri kepada Ida Sang Hyang Widhi Wasa beserta seluruh manifestasi-Nya melalui sebuah upacara yadnya. Pelaksanaan Upacara di Bali merupakan warisan Budaya yang khas yang Kental Pada setiap Masing Masing daerah di bali yang dalam pelaksanaan upacara tidfak terlepas dari gamelan .

Mengenai upacara religius, smith dalam koentjaraningrat (1987 : 67-68) menjelaskan ada tiga gagasan penting mengenai asas religi dalam agama yaitu gagasan yang pertama adalah disamping sistem keyakinan terhadap sebuah upacara, sistem juga merupakan suatu perwujudan dari religi atau agama, gagasan yang kedua adalah bahwa upacara religi atau agama yang biasanya dilaksanakan oleh banyak warga masyarakat pemeluk religi atau agama yang bersangkutan, mempunyai sosial untuk mengidentifikasikan solidaritas masyarakat, gagasan ketiga adalah upacara bersaji merupakan suatu aktivitas untuk mendorong rasa solidaritas dengan dewa atau para dewa.
Dari keterangan tersebut, pementasan Gamelan Gambang pada Upacara Dewa Yadnya dan Pitra yadya dibali tidak terlepas dari : a) Upacara religi atau upacara agama yang dilaksankan oleh masyarakat dibali berupa ritual-ritual keagaman merupakan suatu perayaan (celebration). Untuk mencurahkan rasa kegembiraan masyarakat atas anugrah yang sudah di limpahkan oleh alam semesta dan Ida Sang Hyang Widhi Wasa atau Tuhan yang Maha Esa atas Anugrahnya .

Penyajian Gamelan Gambang dalam Upacara Yadnya merupakan penjabaran dari pelaksanaan ajaran Agama Hindu, yaitu tiga kerangka dasar Agama Hindu yang terdiri dari : Tattwa (falsafah agama), Susila (sikap baik), Upacara (ritual). Ketiga aspek ini merupakan satu kesatuan yang tidak bisa dipisahkan dan selalu digunakan sebagai pedoman oleh umatnya untuk menyelenggarakan upacara keagamaan, dimana didalamnya dijelaskan tentang konsep Kemahakuasaan Tuhan dalam mengatur alam semesta. Ajaran Susila mengajarkan konsep etika dan perilaku umat kepada Tuhan, antara manusia dengan lingkungan tempat tinggalnya. Sedangkan ajaran upacara mengajarkan konsep dan tata cara melakukan ritual keagamaan, yang didalamnya terjalin hubungan manusia dengan Tuhan, manusia dengan sesamanya dan manusia dengan lingkungan (Tri Hita Karana). Ketiga hubungan yang sudah terjalin tersebut dijabarkan kembali dalam ajaran Panca Yadnya.

Masyarakat Bali telah dikenal memiliki aktifltas upacara keagamaan dalam frekwensi yang tinggi. Keseluruhan jenisjenis upacara di Bali digolongkan ke dalam lima macam, yang disebut Panca Yadnya. yaitu:

1. Manusa Yadnya, meliputi upacara daur hidup dan masa kehamilan sampai dewasa. 
2. Fitra Yadnya, meliputi upacara yang ditujukan kepada rohroh leluhur, dan terdiri dan serangkaian upacara, dan upacara kematian sampai pada upacara penyucian roh leluhur.

3. Dewa Yadnya, merupakan upacaraupacara pada pura matipun kuil keluarga.

4. Resi Yadnya, merupakan upacara yang berhubungan dengan pentasbihan pendeta,

5. Bhuta Yadnya, ineliputi upacara yang ditujukan kepada bhuta dan kala yaitu roh-roh disekitar manusia yang dapat menggangu kehidupan manusia.

Sebagai sebuah musik ritual, gamelan Gambang mempunyai peranan yang sangat penting dalam pelaksanaan upacara Yadnya tertentu di Bali. Fungsi dan gamelan Gambang itu mernang bervariasi antara satu daerah dengan daerah lainya, secara mendasar fungsi gamelan gambang di bali sebagai gamelan Pitra yadya

Dengan demikian jika dikaitkan dengan pelaksanaan Gamelan Gambang dalam Upacara, dapat dikatakan memiliki makna religius yang mengandung arti untuk medekatkan diri umatnya kepada yang dipuja, selain itu juga dapat lebih meningkatkan dan melestarikan Gamelan Gambang agar tetap ajeg sampai generasi ke generasi, karena hampir Gamelan Gambang yang ada di bali di atas tahun 80an sudah merupakan gamelan yang disakralkan oleh pelaku masyarakat.

\subsubsection{Nilai Estetika}

Nilai Estetika adalah ilmu yang mempelajari segala sesuatu yang berkaitan dengan keindahan, yang mempelajari semua aspek dari apa yang kita sebut keindahan. Keindahan yang dimaksud adalah keindahan alam dan keindahan buatan manusia yang sering dan disebut kesenian. Dengan demikian kesenian dapat dikatakan merupakan salah satu wadah yang mengandung unsur-unsur kesenian (Djelantik, 1990 : 6).

Gamelan Gambang secara Tehnik permainan dan musikalnya sudah mengandung nilai-nilai keindahan, hal ini dapat diperhatikan dari alunan-alunan melodi lagu yang khas pada barungan gamelan gambang, sehingga secara estetika banyak komposer muda dalam karya baru mentransformasi teknik permaianan gambang seperti tehnik permainan tersebut adalah pukulan Oncang-oncangan merupakan permainan kotekan (interlocking parts) antara Instrumen Gambang yang satu dengan Gambang yang lainnya, yakni setiap instrumen Gambang dimainkan sesuai dengan permainannya masing-masing.

Setiap kesenian sudah barang tentu mengandung nilai-nilai keindahan. Menurut Volket (dalam Gie, 1997:50) menegaskan bahwa tentang perpaduan dua bentuk teori estetis yang obyektif dan ini pengalaman yang subyektif menyatakan empat ukuran yang menjadikan tanda pengenal dari karya seni yang dianggap memuaskan secara estetis yaitu keselarasan antara bentuk dan isi Pada Struktur Gambang Pada Umumnya

Struktur gending Gambang pada umumnya terdiri dari: Pengrangrang atau gineman, kawitan (Ping pisan), Ping Pindo, Ping Tiga, Ping pat dan Penyuwud.

Pengrangrang dan gegineman : Merupakan bagian yang paling awal dalam sebuah komposisi gending gambang. Bagian mi dimainkan o! eh semua instrumen dengan menggunakan gegebug kekenyongan dan dalam tempo yang agak bebas. Bagian mi merupakan pengenalan saih atau patet gending yang akan dimainkan.

Kawitan (Ping Pisan): sesungguhnya istilah Ping Pisan berasal dan kata Kaping pisan yang artinya bagian yang pertama. Pada bagian disemua instrumen bermain 
dengan teknik kekenyangan dengan tempo yang pasti. Kawitan atau ping pisan biasanya diulang sebanyak dua kali, setelah itu dilanjutkan ke Ping Pindo.

Ping Pindo: Bagian kedua yang merupakan bagian Pengawak pertama dan sebuah komposisi gending Gambang. Bagian ini dengan jelas dapat dibedakan dengan Ping Pisan, terutama melalui teknik pukulan yang dipergunakan oleh intrument gangsa maupun gambang. Di sini gangsa akan memegng melodi pokok dengan teknik kekenyongan dan agal sedangkan ke empat gambang akan membuat oncang-oncangan,

Ping Tiga: Merupakan bagian pengawak yang kedua, teknik pukulannya sama dengan Ping Pindo.

Ping Pat: Bagian pengawak setelah Ping Tiga , gegebug yang sama dengan Ping Pindo dan Ping Tiga. Dalam istilah pengulangan pengawak dengan lagu yang sama akan di ulang dengan istilah ping pindo, Tiga, pat

Penyuwud: Artinya bagian penutup atau paling akhir. Penyuwud dapat dibedakan dengan jelas dan bagian sebeluinnya karena path bagian mi semua instnimen secara bersama-sama inenggunakan teknik gegebug nyading dan Nyingkal.

\subsubsection{Nilai Etika}

Kata etika berasal dari bahasa Yunani yaitu "ethos" yang mempunyai banyak arti seperti watak, perasaan, sikap, prilaku, karakter, tata karma, tata susila, sopan santun, cara berfikir dan lain-lain. Dalam Agama Hindu, etika dinamakan "Susila". Kata susila berasal dari dua suku kata yaitu $s u$ yang berarti baik dan sila yang berarti kebiasaan atau tingkah laku yang baik. Mempelajari segala bentuk pengetahuan selalu diperlukan adanya suatu tata prilaku yang baik dalam menguasai pengetahuan tersebut. Sama halnya dengan mempelajari suatu bentuk kesenian, diperlukan tata prilaku yang baik agar dapat menguasai kesenian tersebut. Tanpa adanya etika (prilaku) yang baik, kesenian tersebut tidak dapat dikuasai dengan baik.

Nilai pendidikan etika dalam agama Hindu yang terdapat dalam Gamelan Gambang adalah penerapan ajaran Tri Kaya Parisudha, yaitu terdiri dari Manacika yang berarti berfikir yang baik dan benar, Wacika berarti berkata yang baik dan santun, Kayika berarti berbuat yang baik dan benar. Manacika Parisudha (pikiran yang baik dan benar), pikiran merupakan sumber dari segala apa yang dilakukan orang, sebab para penabuh (pemain Gambang) sebagai manusi sebelum melakukan sesuatu terlebih dahulu hendaknya dipikirkan. Halinimengakibatkan pikiran harus dikendalikan dari pengaruhpengaruh yang tidak baik, seperti disebutkan dalam kitab Sarascamuscaya sloka 80, sebagai berikut :

Apan ikang manah ngaranya ya, ya ika witning indra, maprawerti taya ring subha karma, matangyan ikang manah juga prihen kahrtanya sakareng.

Terjemahannya :

Sebab yang disebut pikiran itu adalah sumber nafsu, ialah yang menggerakan perbuatan baik maupun perbuatan buruk, oleh karena itu pikiranlah yang segera patut diusahakan pengekangannyaataupengendaliannya (Kanjeng, 1995:44).

Seloka diatas menunjukan bahwa pikiranlah yang dapat mengegerakan manusia untuk berbuat baik dan buruk, oleh karena itu usahakanlah untuk mengendalikan pikiran agar tidak mengarah ke hal-hal yang bersifat buruk. Segala tindakan manusia harus didasari pemikiran dan pertimbangan matang, sehingga apa yang direncanakan 
akan mencapai tujuan yang diinginkan.

Wacika Parisudha merupakan perkataan yang baik dan suci, hal ini sebenarnya berawal dari pikiran, karena perkataan akan timbul setelah adanya proses berfikir. Berkaitan dengan Gamelan Gambang, sangat diharapkan bagi para penabuh (pemain) dapat menjaga perkataannya, sebab bila perkataan kotor seperti berkata kasar, mencaci maki, menghina, dan menfitnah adalah hal yang tidak pantas diucapkan oleh seorang penabuh, jika hal ini dilanggar maka kesuciannya akan hilang. Hal ini mengakibatkan perkataan harus dikendalikan dari pengaruh-pengaruh yang kurang baik, seperti yang disebutkan dalam kitab Sarascamuscaya sloka 177, sebagai berikut :

Kunang ling mami, rwa ikang nimittang wwang inastuti iwiraya, ikang pasaningu mujarakenang parusawacana, ikang pisaningu kumira-kirang ulah tan yukti kunang, samangkana wwang pinujin haneng rat

Terjemahan :

Maka hamba berpendapat, bahwa adalah dua macam perbuatan yang menyebabkan orang terpuji, misalkan sekali-kali tidak mengucapkan perkataan kasar, sekali-kali tidak memikirkan perbuatan yang tidak layak, maka orang yang berkeadaan demikianlah yang terpuji di dunia.

Sloka di atas menunjukan bahwa perkataan yang membuat orang menjadi terpuji, oleh karena itu usahakanlah untuk menjaga perkataan agar tidak mengarahkan manusia ke hal-hal yang bersifat buruk.

Kayika Parisudha merupakan suatu perbuatan yang harus di sucikan, perbuatan merupakan realisasi dari sebuah hasil pemikiran. Perbuataan perlu dikendalikan karena ketika melakukan perbuatan yang salah maka kesengsaraanlah yang akan ditemukan, dan bila perbuatan itu baik dan penuh dengan kesucian maka kebahagiaan yang dapat diterima.

Pemain Gamelan Gambang sangat menekankan prilaku, karena prilaku inilah yang mudah dilihat. Seorang penabuh memiliki kerendahan hati, yang didasari oleh Srada dan Bhakti. Masyarakat betulbetul mengabdikan dirinya dengan tulus iklas. Selain ajaran Trikaya Parisudha tersebut diatas, etika dalam gamelan dibahas juga dalam sebuah hasil kesusastraan, yaitu pada lontar Prakempa yang merupakan sumber etika masyarakat dan dapat dijadikan bahan pelajaran etika bagi masyarakat. Prakempa membahas masalah bahwa bunyi (suara) memunyai kaitan yang erat dengan konsep si lima dimensi yang dinamakan Panca Mahabhuta, yaitu Pertiwi, Bayu, Apah, Teja, dan Akasa. Pencipta dari bunyi itu bernama Bhagawan Wiswakarma dan ciptaan beliau mengambil ide dari bunyi (suara) delapan penjuru dunia yang sumbernya berada pada dasar bumi. Suara itu dibentuk menjadi sepuluh nada yaitu lima nada yang disebut dengan Laras Pelog dan lima nada yang disebut dengan Laras Selendro. Nada-nada ini mempunyai kaitan dengan Panca Tirta dan Panca Geni, dua keseimbangan hidup manusia. Dalam Prakempa ini dibahas juga berjenis-jenis konsep keseimbangan hidup manusia dalam berbagai dimensi di atas, memberikan petunjuk pada kita bahwa Prakempa ini merpersoalkan masalah etika, khususnya dipandang dari sudut perbuatan baik dan buruk manusia.

Mengenai aspek etika yang lain yang dibahas dalam lontar Prakempa ialah apa yang dinamakan "Kutukan". Bagi seorang guru gamelan diwajibkan untuk menghayati falsapah dasar dari Prakempa ini, berikut 
aturan-aturan kesusilaan yang terkandung didalamnya. Bagi mereka yang tidak mengindahkan itu akan terkena kutukan yang sangat dasyat, dimana arwah mereka tidak akan mendapat sorga bahkan mereka akan menjadi dasar kawah neraka. Mereka tidak dibenarkan untuk menitis sebagai manusia, melainkan akan menjadi rayap yang selalu dihina oleh manusia (Bandem, $1986: 15-16$ ).

Etika permainan Gamelan Gambang merupakan pembentukan karakter. Mempelajari Gamelan Gambang memerlukan pedoman prilaku yang harus dipatuhi dan diikuti. Pedoman tata prilaku tersebut adalah tidak boleh melangkahi gamelan yang berarti menyalahi etika, karena gamelan tersebut diyakini memiliki unsur Panca Maha Bhuta serta bahwa bunyi gamelan tersebut dipercaya diciptakan oleh Bhagawan Wiswakarma. Diperlukannya kesabaran yang tinggi dan rasa disiplin yang tinggi serta konsentrasi penuh ketika mempelajari Gamelan Gambang. Dengan mempelajari Gamelan Gambang ini, maka akan dapat menumbuhkan prilaku yang baik dimana rasa sabar, tulus, disiplin serta keluetan dapat dilatih dalam mempelajari gamelan ini.

\subsection{Penutup}

Gamelan Gambang terrmasuk kedalam golongan gamelan tua dapat dilihat dari barungan gamelan tersebut belum menggunakan alat membranofon(kendang), yang dapat di fungsionalkan bergai aktifitas kegiatan dalam pelaksanaan upacara Yadya Dibali akan tetapi khasan dalam pitra yadya yang mengisyaratkan gambang menjadi khusus di bali, dalam pelaksanaannya, adapun bebrapa nilai yang terkandung dalam gamelan gambang yaitu: nilai religius jika dikaitkan dengan pelaksanaan Gamelan Gambangdalam setiap pelaksanaan Dewa dan Pitra Yadya di bali, dapat dikatakan memiliki makna religius yang mengandung arti untuk medekatkan diri umatnya kepada yang dipuja, dan mencerminkan rasa bakti kepada Tuhan Yang Maha Esa/Ida Sang Hyang Widhi Wasa beserta manifestasi-Nya, yang diwujudkan melalui persembahan pelaksanaan upacara keagamaan yang berdasarkan ajaran Agama Hindu di Bali. Nilai estetika ini dapat diperhatikan dari Kehadiran gamelan gambang dalam upacara memberikan khusukan dalam pelaksaanya alunan-alunan melodi lagu atau gending dalam rasa keagungan, rasa merinding, dan rasa terpesona. Nilai etika Gamelan Gambang para penabuh sangat menekankan prilaku, menabuh didasari oleh Srada dan Bhakti. Mempelajari Gamelan Gambang memerlukan pedoman prilaku yang harus dipatuhi dan diikuti. memiliki unsur Panca Maha Bhuta serta bahwa bunyi gamelan tersebut dipercaya diciptakan oleh Bhagawan Wiswakarma.

\section{DAFTAR PUSTAKA}

Bandem, I Made. 2013. Gamelan Bali Di Atas Panggung Sejarah. Denpasar : BP Stikom Bali , 1991. Ubit-ubitan Sebuah Teknik Permainan Gamelan Bali. Denpasar : Ditjen Pendidikan Tinggi DKPDIKBUD , 1986. Prakempa Sebuah Lontar Gamelan Bali. Denpasar : Sekolah Tinggi Seni Indonesia Denpasar.

Dibia, I Wayan. 1977. Pengntar Karawitan Bali. Denpasar : Akademi Seni Tari Indonesia

Djelantik, 2008. Estetika Sebuah Pengantar. Jakarta : MSPI

Donder, I Ketut. 2005. Esensi Bunyi 
Gamelan Dalam Prosesi Ritual Hindu. Denpasar : Paramita

Kanjeng. 1995. Dalam Skripsi Widari. 2014. Eksistensi Drama Tari Di Desa Pekraman Dlod Blungbang, Kecamatan Tegalalang, Gianyar (Kajian Nilai Pendidikan Agama Hindu). Denpasar : UNHI

Kanisisus. 2006. Dalam Skripsi Widari. 2014. Eksistensi Drama Tari Di
Desa Pekraman Dlod Blungbang, Kecamatan Tegalalang, Gianyar (Kajian Nilai Pendidikan Agama Hindu). Denpasar : UNHI

Gie, The Liang, 1997.Filasfat Keindahan , Pusat belajar ilmu berguna (PUBUB): Yogyakarta :Cv adiputra 